\title{
Erratum to: 'Cool' adaptations to cold environments: globins in Notothenioidei (Actynopterygii, Perciformes)
}

\author{
Daniela Giordano • Roberta Russo • \\ Daniela Coppola $\cdot$ Giovanna Altomonte $\cdot$ \\ Guido di Prisco $\cdot$ Stefano Bruno $\cdot$ Cinzia Verde
}

Published online: 28 September 2015

(C) Springer International Publishing Switzerland 2015

\section{Erratum to: Hydrobiologia \\ DOI 10.1007/s10750-015-2306-1}

Due to an unfortunate turn of events, the current affiliation of the fourth co-author was omitted from the original publication. The correct list of authors and their affiliations is published here and should be treated as definitive by the reader.

The online version of the original article can be found under doi:10.1007/s10750-015-2306-1.

D. Giordano - R. Russo - D. Coppola

G. Altomonte - G. di Prisco · S. Bruno · C. Verde $(\square)$ Institute of Biosciences and BioResources, CNR, Via Pietro Castellino 111, 80131 Naples, Italy

e-mail: c.verde@ibp.cnr.it; cinzia.verde@ibbr.cnr.it

G. Altomonte · C. Verde

Department of Biology, Università Roma Tre, Viale

Marconi 446, 00146 Rome, Italy

S. Bruno

Department of Pharmacy, University of Parma, Parco

Area delle Scienze 23/A, Parma, Italy 